\title{
Reaction of Tomato Cultivars to a Sublethal Dose of Glyphosate
}

\section{V.M. Russo \\ U.S. Department of Agriculture/Agricultural Research Service, South Central Agricultural Research Laboratory, POB 159, Lane, OK 74555}

Additional index words. yield, nontarget organism, herbicide, Lycopersicon esculentum

Tomato (Lycopersicon esculentum Mill. cvs. Sunny, Jet Star, and FloraDade) were accidentally exposed to drift from a $4.5 \%$ (concentrate to total volume) solution of glyphosate herbicide (Roundup) applied at 3.4 $\mathrm{kg} \cdot \mathrm{ha}^{-1} 64 \mathrm{~m}$ to the south. The air was at $21.5 \mathrm{C}$ and wind speed was 1.9 to $3 \mathrm{~km} \cdot \mathrm{hr}^{-1}$ from the south. All plants exhibited chlorosis of new leaves and of the terminal bud, indicating damage from spray drift. Two weeks after exposure, no plants had died, so the concentration was judged to be sublethal. The original plot design consisted of the three cultivars in three treatments in three completely randomized blocks with plants on 46$\mathrm{cm}$ centers. Plants were fertilized in-row before bed formation, and water was supplied by drip irrigation. The original objective of the field experiment was terminated and effects of a sublethal dose of glyphosate, applied before flowering, on growth and yield of the cultivars noted was examined.

Harvests were begun 10 weeks after transplanting. 'Sunny' had higher total and marketable yields than the other cultivars (Table 1). Only $38 \%$ (range $37 \%$ to $41 \%$ ) of fruit were marketable. On average, $46 \%$ of fruit in this study were rejected due to small size (39\%, 'Jet Star'; 48\%, 'Sunny'; .50\%, 'FloraDade'). Of the remaining $\approx 16 \%$ of fruit, which were of marketable size, $\approx 10 \%$ were rejected for cracks and $\approx 3 \%$ each for insect damage or disease.

A greenhouse experiment was conducted to determine the amount of the glyphosate solution necessary to cause the symptoms observed in the field. Five 7-week-old seedlings of each cultivar/dosage were transplanted in Terra-lite Redi-earth (Grace Prod., Cambridge, Mass.) potting soil in 0.946-liter pots. After 1 week, an artist's airbrush (Toler and Herbert, 1965) was used to apply 0.075 , $0.1,0.2,0.4,0.6,0.8$, or $1.0 \mathrm{ml}$ of the $4.5 \%$ glyphosate solution uniformly to plants, including the terminal bud and new leaves.

Received for publication 2 Apr. 1990. The cost of publishing this paper was defrayed in part by the payment of page charges. Under postal regulations, this paper therefore must be hereby marked advertisement solely to indicate this fact.
Plants treated with $1.0 \mathrm{ml}$ of water were used as controls. Color change was monitored using a calorimeter (Minolta CR-200, Minolta Camera, Japan). Values were measured as A (change green to red), and B (change blue to yellow). Before application (0 hr), five readings per plant were made on leaves that would receive treatment. At $5 \mathrm{hr}$ after application, before symptom expression, five readings per plant for all dosages were made on treated leaves. Subsequent readings were made on symptomatic leaves.

$A$ and $B$ values described significant cubic distributions (Fig. 1) with no differences among cultivars due to treatment, A values for all dosages had increased by $5 \mathrm{hr}$ after application and again by $20 \mathrm{hr}$ and then stabilized. Values of B increased between 20 and $72 \mathrm{hr}$ after application of all dosages; by that time, leaves sprayed with dosages subsequently determined to be lethal exhibited necrosis. After $72 \mathrm{hr}$, readings were only from chlorotic leaves. By $90 \mathrm{hr}$, B values were still greater than initial values. These findings represent destruction of chlorophyll and onset of necrosis, and indicate that dam-

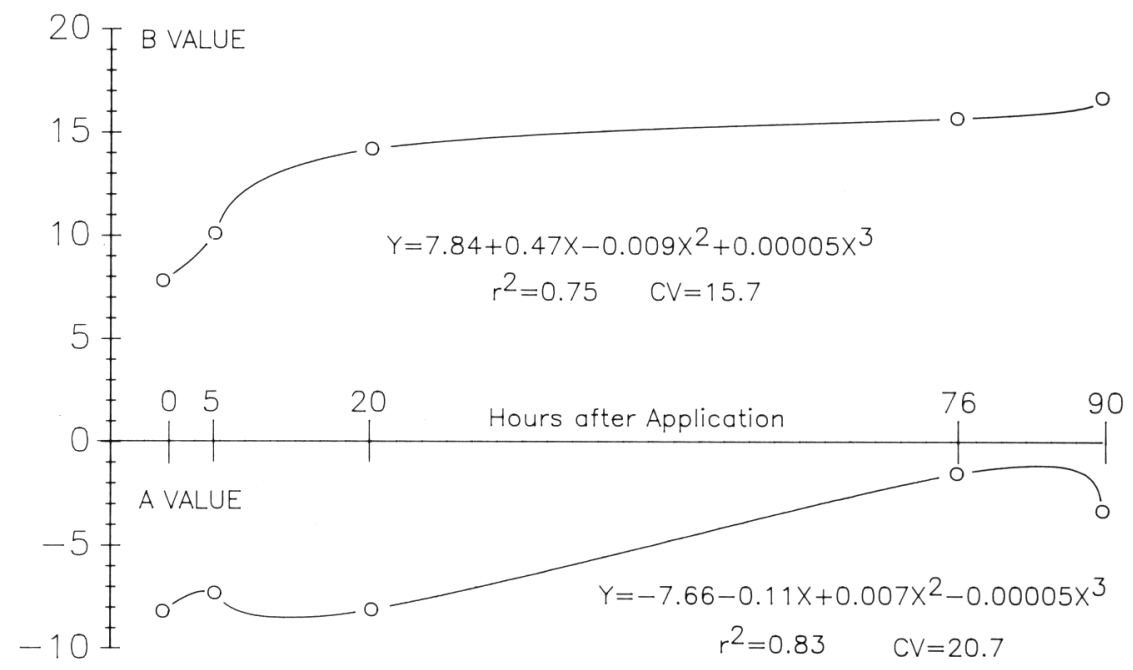

Fig. 1. Changes in calorimetric readings (A and B values), through $90 \mathrm{hr}$ postapplication, for 7-weekold tomato plants, averaged over all cultivars. Readings before $72 \mathrm{hr}$ are from plants treated with all dosages of the $4.5 \%$ glyphosate solution. Readings at 72 and $90 \mathrm{hr}$ are from leaves that were not necrotic. 